\title{
Formação em Psicologia Social: relato de uma EXPERIÊNCIA DE ENSINO/PESQUISA/INTERVENÇÃO http://dx.doi.org/10.1590/1984-0292/930
}

\author{
Angela Maria Dias Fernandes ${ }^{I, \star}$, Andrea Vieira Zanella ${ }^{I I}$, Gabriel Bueno ${ }^{I I}$ \\ ${ }^{I}$ Universidade Federal da Paraíba, João Pessoa, PB, Brasil \\ ${ }^{\text {II }}$ Universiade Federal de Santa Catarina, Florianópolis - SC, Brasil
}

\section{Resumo}

O objetivo deste texto é apresentar e discutir um trabalho educativo em que foram experimentadas três estratégias de intervenção metodológica e teoricamente articuladas com um grupo de estudantes de psicologia. A concepção de "grupo como dispositivo" foi afirmada em todo o processo, sendo condição para a constituição de conexões e o processo de produção de sentidos. As experimentações engendradas na disciplina foram analisadas através de uma atividade de autoavaliação promovida ao final do semestre letivo, sendo as observações dos alunos indicativas da relevância da intervenção realizada para a formação crítica do profissional em psicologia.

Palavras-chave: formação; pesquisa-intervenção; psicologia social.

\section{Training professional in Social Psychology: Report OF A TEACHING EXPERIENCE / RESEARCH / INTERVENTION}

\begin{abstract}
The aim of this paper is to present and discuss an educational work in which they were tried three strategies of collective intervention in a group of psychology students. The methodology and theoretical formulations were articulated in this propose. The concept of "group as a device" was affirmed throughout the process as a condition for the establishment of connections and the process of meaning production. The trials were analyzed in the discipline engendered by the activity of self-evaluation promoted by the end of the semester, which revealed the importance of intervention aimed at training professional critique of psychology.
\end{abstract}

Keywords: training; intervention research; social psychology.

\footnotetext{
^Endereço para correspondência: Universidade Federal da Paraíba, Centro de Ciências Humanas Letras e Artes - Campus I, Departamento de Psicologia. Cidace Universitária - Campus I Cabo Branco. 58059-900 - Joao Pessoa, PB - Brasil.E-mail: angeladfernandes@yahoo.com.br, avzanella@gmail.com,gbapsi@gmail.com
} 


\section{INTRODUÇão}

O objetivo deste texto é apresentar e discutir estratégias de intervenção, no coletivo de alunos, desenvolvidas em uma disciplina do curso de graduação em Psicologia de uma universidade pública brasileira, intitulada Psicologia Social II e ministrada no sexto período. Participaram do processo 39 estudantes de Psicologia regularmente matriculados na disciplina, sendo esta coordenada por um docente da universidade, um docente em estágio pós-doutoral e um mestrando em Psicologia. Foram realizados 18 encontros ao longo de quatro meses, no ano de 2011, com duração média de 3 horas e 30 minutos cada.

O programa da disciplina ministrada compreendia cinco unidades. As duas primeiras unidades foram dedicadas ao estudo do referencial histórico/conceitual do curso, tratando de temáticas como a construção histórica da psicologia social; as contribuições do materialismo histórico e dialético; a constituição do sujeito na perspectiva histórico-cultural; a mediação semiótica do psiquismo humano e modos de subjetivação. Na terceira unidade foram focalizadas teorias relacionadas à concepção de grupo valorizando a força de intervenção social e coletiva, os movimentos sociais e suas formas de emergência na atualidade. Na unidade seguinte foi trabalhada a importância da pesquisa na psicologia social e da implicação dos sujeitos no ato investigativo. A última parte do curso foi dedicada a práticas de pesquisa/intervenção, sendo tratada a interface da psicologia social com vários campos e temáticas: política, comunidade, violência, educação, trabalho, arte e saúde. Foram definidas três estratégias de intervenção no coletivo de alunos e que consistiram em recursos para avaliação do processo formativo, a serem analisadas neste texto: a produção de imagens via desenho, a produção de um vídeo e de um texto escrito.

Analisar essa experiência desenvolvida em uma sala de aula se apresenta como desafio, uma vez que a produção bibliográfica que dá suporte a este programa de curso está intimamente articulada com os princípios norteadores da proposta de intervenção educativa que será aqui analisada. O principal dentre estes princípios é a perspectiva da crítica à neutralidade tanto do trabalho educativo como do processo de produção de conhecimentos, posto a implicação dos sujeitos nos processos de ensinar e aprender bem como na formulação das interrogações e na escolha dos caminhos investigativos. Se por um lado a complexidade dos processos de ensinar e aprender, as tensões que os conotam e seus efeitos para as pessoas que os engendram são problematizados por pesquisadores de variadas orientações teóricas e metodológicas (SCHLINDWEIN; SIRGADO, 2006; ROCHA, 2008; FREIRE, 2009; entre outros), a análise da implicação no processo de pesquisar vem sendo apontada como fundamental à produção de conhecimentos outros, pautados pelo reconhecimento da intrincada relação entre pesquisador e as pessoas com as quais pesquisa (MAIRESSE; FONSECA, 2002; COSTA; COIMBRA, 2008; PAULON, 2005; NASCIMENTO; COIMBRA, 2008).

A essas questões se entretece o foco de ensino na disciplina, a saber, os conhecimentos da psicologia social não clássica, alicerçados na compreensão de que os sujeitos se constituem via relações com outros sujeitos em contextos 
sociais e históricos específicos, relações essas mediadas pela cultura e fundantes das relações com os outros e consigo mesmo. Afirma-se com as discussões propostas um processo de escolhas éticas, estéticas e políticas, o compromisso "com as possibilidades de vida em suas diferentes manifestações balizadas pelas condições de conviviabilidade" (GROFF; MAHEIRIE; ZANELLA, 2010, p. 99).

A formação profissional - tal como é aqui concebida e que balizou o trabalho com os alunos - se constitui como um campo de estranhamento, afirmativa dos espaços de coletivização que possibilitam o deslocamento dos sujeitos. No trabalho de intervenção que será aqui analisado, parte-se da formulação de propostas de ação educativa que façam movimentar os grupos constituindo um terreno propício ao estranhamento em relação aos instituídos, à experimentação e ao debate.

A pesquisa em sala de aula, se tomada nessa perspectiva, pode reposicionar professores e alunos diante da possibilidade de construir um cotidiano escolar onde a dialogia ${ }^{1}$ e a invenção se façam presentes. Alunos objetivados como figuras inertes tais como os da educação bancária problematizada por Paulo Freire (1970), são postos em questão, assim como professores alheios ao lugar social de saber/ poder que ocupam. Tendo essa aposta como horizonte, serão analisadas as três estratégias identificadas como centrais no desenvolvimento da disciplina em foco.

\section{ESTRATÉGIAS DE INTERVENÇ̃̃o EDUCATIVA}

A primeira unidade do curso consistiu na base teórica que possibilitou a emergência de uma psicologia social outra, sendo priorizada nas discussões a concepção de história e de psicologia social como um espaço de crítica e de produção. Introduzir a concepção dialética e dialógica (FARACO, 2003; BRAIT, 2005; GROFF; MAHEIRIE; ZANELLA, 2010) na formação dos estudantes de psicologia significou abrir um campo de circulação de conhecimentos que confrontam os modelos tradicionais e totalizantes. A leitura e o debate de textos foram, nessa unidade, priorizados, sendo as estratégias de intervenção educativas eleitas como foco de análise neste texto desenvolvidas nas demais unidades da disciplina.

\section{Primeira estratégia: diálogo e conexão entre imagens}

Ao introduzir a segunda unidade do curso, foi definida a primeira estratégia educativa. Os exercícios propostos estavam relacionados às teorias grupalistas e focalizavam as formulações de Michel Foucault e Gilles Deleuze, partindo da concepção de grupos como processualidade, como "dispositivos de fazer ver e falar" (RODRIGUES, 1999; BARROS, 1997; SOARES, 2011), buscando a experimentação do conceito de conexão e constituindo aberturas para ouvir/criar outros modos de subjetivação. Neste texto é utilizado o conceito de dispositivo tal como proposto por Gilles Deleuze (1990, online):

uma espécie de novelo ou meada, um conjunto multilinear. É composto por linhas de natureza diferente e essas linhas do dispositivo não abarcam nem delimitam sistemas homogêneos por sua própria conta (o objeto, o sujeito, a linguagem), mas seguem direções diferentes, formam 
processos sempre em desequilíbrio, e essas linhas tanto se aproximam como se afastam uma das outras.

Sendo um conjunto multilinear, o dispositivo faz ver e falar e isso foi o que justamente procuramos engendrar com as estratégias educativas propostas. Barros (1997, p. 186), ao afirmar o grupo como "dispositivo em ação" que produz conexões, nos diz que

A realidade não está, assim, repleta de objetos para serem conhecidos, decodificados por um sujeito que lhe transcenda. Ela é feita de modos de iluminação e de regimes discursivos. O saber é a combinação dos visíveis e dizíveis de um estrato, não há nada antes dele, nada por debaixo dele.

No trabalho grupal, a autora chama atenção para as conexões que se fazem não só entre pessoas, mas entre modos de subjetivação diferentes. Não se trata somente de estabelecer espaços de articulação entre o que está dado, mas de produção, de invenção do novo, do múltiplo, do imprevisível. Criar possibilidades do diverso, do não conhecido. Neste momento da disciplina a tentativa foi de qualificar o grupo da forma como nos diz Barros (1997, p. 189; 199), ou seja, como espaço em que o “"experimentar ouvir o outro' irradia uma experimentação de ouvir outros - outros modos de existencialização, outros contextos de produção de subjetividades, outras línguas para afetos, outros modos de experimentar”.

Uma oficina de produção de imagens, inicialmente individuais, e o estabelecimento de um campo de agenciamentos via produção de textos imagéticos coletivos, em um segundo momento, possibilitaram a compreensão desta referência teórica. Inicialmente foi orientada uma atividade individual de traçar linhas aleatórias, em uma folha de papel em branco, estando os participantes com os olhos fechados. A definição, por parte de cada aluno de uma imagem em meio aos próprios traços feitos ao acaso, foi o segundo processo experimentado, sendo proposta a seguir a produção de um desenho a partir desta imagem. Posteriormente, foi solicitado que todos, caminhando pela sala, apresentassem seus desenhos aos colegas, tentando encontrar pontos de conexão entre eles. Segundo a orientação dada, os alunos deveriam constituir grupos encontrando elementos potencializadores do estabelecimento das conexões. Foram assim constituídos cinco grupos. Cada grupo apresentava o conjunto de desenhos reunidos e explicava aos demais grupos o processo experimentado na produção/identificação de conexões. Essa experiência era traduzida em um argumento que sustentava a ideia coletiva produzida pelo grupo.

O primeiro grupo a apresentar seu trabalho foi composto por dois alunos. Segundo sua apresentação, depois de várias experimentações em busca de estabelecer conexões com outros colegas, concluíram pela identificação de linhas sinuosas, dispostas em uma parte do papel, que se destacavam nos dois desenhos e que, segundo seus autores, não guardavam nenhuma relação com alguma forma ou objeto que pudesse ser nomeado. A conexão experimentada era pela ausência de significado e pela semelhança no traço. 
O segundo grupo foi constituído por seis alunos. A conexão produzida foi desencadeada por um desenho identificado pelos participantes como uma fábrica. Foram a ele associados os desenhos de uma gravata e de um animal com chifres, interpretados como o dono da fábrica. Em outros quatro desenhos foi identificada, em uma forma oval, variações de olhos que, segundo relato do grupo, significava a existência de observadores na fábrica. Um último desenho, que apresentava contornos semelhantes a um cavalo, foi interpretado como os trabalhadores. $\mathrm{Na}$ apresentação do grupo, ainda, foi sublinhada a vivência de uma situação de poder identificada nos signos representados nos desenhos.

O grupo três, composto por seis estudantes, formou conexões por um aspecto que parecia central nas imagens que trazia uma possibilidade de "iluminação". O sol, em um dos desenhos, complementado por uma casa e uma flor ganhou centralidade neste grupo. Os demais desenhos foram identificados por uma irradiação de luz, através de formas coloridas, com centros bem definidos e pontas abertas indicando um semicírculo. Segundo a argumentação deste grupo, as conexões foram produzidas a partir do desenho do sol que fazia produzir novos significados para cada forma identificada.

O quarto grupo foi se constituindo a partir da reunião de três subgrupos que criaram conexões em função de formas abstratas bem delimitadas, conforme foi defendido por seus sete participantes. Inicialmente se conectaram duas imagens onde foram identificados elementos associados a uma letra. A posição do desenho na folha foi outro elemento que permitiu o pertencimento ao grupo, além das formas circulares utilizadas. Nessa outra conexão ficou clara uma marca diferenciadora designada como formas abstratas que iam ganhando referência na identificação com as demais.

O último grupo a fazer a apresentação de seu material relatou que, ao se constituir como coletivo, seus oito participantes experimentaram certas escolhas e recusas constituindo-se um modo específico de funcionar. Foram sendo articulados desenhos e atribuídos significados que promoviam a busca de sua produção. Os desenhos tinham formas abstratas e muito coloridas, o que foi identificado como o elemento que possibilitou os encontros e a produção de uma formulação em aberto para novos significados.

A discussão coletiva das conexões produzidas, dos sentidos produzidos para os desenhos pelos componentes de cada grupo e que resultou em inclusões e exclusões, foi tensionada. Os movimentos de alguns grupos e também de cada pessoa no sentido de promover aproximações e distanciamentos foram tensionados, sendo problematizadas as relações nós/eles, a falsa oposição coletivo/singular, os agenciamentos que esses discursos sustentados por teorizações da própria psicologia social produzem.

Após a atividade, desenvolvida em uma aula, foi solicitado aos alunos que fizessem um relato escrito da experiência, buscando uma reflexão do texto indicado como bibliografia básica. Este material e o debate, ocorrido em 
seguida ao trabalho com os desenhos na sala de aula, permitiram o questionamento de algumas concepções de grupo como "soma de indivíduos ou partes" e de sociedade como totalização.

A proposição de Barros (1997), pesquisadora indicada aos alunos como base para o estudo do tema grupos em psicologia social, aponta para o delineamento das linhas que vão se traçando no estabelecimento de conexões, marcando pontos de ruptura. Para esta autora, "não há sentidos a serem revelados, mas a serem criados" (BARROS, 1997, p. 189).

Nos relatos dos alunos ficou evidente a potência da experiência na aproximação com essa forma de conceber o grupo que escapa da concepção presente na maioria dos livros textos de psicologia social. A vivência grupal e o estabelecimento de conexões foram traduzidos como criação coletiva, onde formas foram ganhando sentidos, ressaltando-se a capacidade de promover identificações e diferenciações.

\section{Segunda estratégia: a produção de painéis}

A segunda estratégia educativa foi montada buscando trabalhar a noção de implicação, em contraposição à de neutralidade na ação investigativa, ressaltando sua importância na produção do conhecimento, sendo tratados os temas da quarta unidade da disciplina em foco. Para Rocha e Aguiar (2003, p. 72), a análise da implicação consiste na

análise do sistema de lugares ocupados ou que se busca ocupar ou ainda do que lhe é designado, pelo coletivo, a ocupar e os riscos decorrentes dos caminhos em construção. A análise das implicações com as instituições em jogo nas situações afirma também a recusa da neutralidade do analista/pesquisador, procurando romper com as barreiras entre sujeito que conhece e objeto a ser conhecido. A intervenção evidencia que pesquisador/pesquisado, ou seja, sujeito/objeto, fazem parte do mesmo processo.

Após o debate teórico sobre o tema e o estabelecimento de relações com a psicologia social, foi dedicada uma aula para que, em uma atividade dinamizada com o conjunto de alunos, fossem sistematizadas as questões centrais trabalhadas a partir da leitura das referências bibliográficas indicadas (COSTA; COIMBRA, 2008; ZANELLA; SAIS, 2008).

Seis temáticas foram definidas e apresentadas para o grupo em slides na forma de palavras ou frases: 1 - pesquisar é intervir; pesquisa-intervenção; 2 - experimentar; pensar; perguntar; 3 - pergunta; método; referencial teórico; dispositivo; 4 - complexidade; pesquisar é criar; 5 - pesquisa como prática social, ética, estética e política; pesquisa como produção histórica e social; 6 - implicação.

A turma foi então dividida em seis grupos. Através de um sorteio, foi designada uma temática para cada grupo e solicitado aos participantes que elaborassem uma imagem, em uma folha de papel kraft, polemizando a temática. Os grupos trabalharam por 40 minutos e, posteriormente, apresentaram seus trabalhos. 
No tema 1 as expressões "pesquisar é intervir"; "pesquisa-intervenção" foram demonstradas pela figura de um olho ao centro e vários braços com mãos abertas estendidas saindo do contorno do desenho do olho. Das bordas do papel em direção ao desenho central também foram pintados braços e mãos como se estivessem buscando tocar aquelas que estavam ligadas ao olho. Na apresentação o grupo formulou a ideia de que se tratava de um olho investigativo que tudo tocava e era tocado por tudo, significando a possibilidade de intervenção.

As palavras “experimentar"; "pensar"; "perguntar" foram representadas por um painel que continha um conjunto de setas direcionadas para o centro do desenho. No alto, à esquerda foram desenhadas estrelas e à direita, ondas. No canto esquerdo abaixo da folha foram representados quatro pequenos desenhos: um olho aberto; um redemoinho; um sinal de interrogação e símbolo de triângulos dispostos como se fossem setas voltadas para um centro vazio. O grupo buscou definir as três palavras como uma abertura para o novo. Uma particularidade dos desenhos criados era a utilização de símbolos que, tradicionalmente, representavam um caminho e um movimento, embora se dirigissem a um centro definido e restrito.

O terceiro painel apresentado dedicava-se a explorar o tema da produção do conhecimento a partir das seguintes expressões: "a pergunta"; "método"; "referencial teórico"; "dispositivo". O grupo elaborou um painel que utilizava diversas formas, simbolizando o sinal da interrogação. Em um canto o desenho de um homem e vários balões com o mesmo símbolo. De outro, a representação da terra com uma grande interrogação, um navio no oceano e, outro balão, com o mesmo símbolo dirigido ao sol, colocado no canto esquerdo da folha. No canto direito superior foi desenhado um globo ocular. Na exposição foi sinalizada a importância da pergunta no ato investigativo e na descoberta de novos horizontes, simbolizada pelo barco em busca de territórios inexplorados.

O painel que representava a palavra "complexidade" e a expressão "pesquisar é criar" trazia um desenho da terra circundada pelo símbolo utilizado para indicar a presença de energia nuclear. Duas setas estavam voltadas em direção a este símbolo e uma terceira seta indicava uma saída a partir deste símbolo. $\mathrm{Na}$ exposição, o grupo relacionou as duas expressões sinalizando limites na criação dados pela noção de complexidade.

O quinto painel foi dedicado a expressar as temáticas: "pesquisa como prática social, ética, estética e política"; "pesquisa como produção histórica e social". O grupo desenhou uma figura humana com uma prancheta à sua frente e, no canto direito abaixo, dois homens e uma mulher. No fundo, um edifício com antenas de TV e uma casa ao lado. Foi sinalizada a importância da conexão entre os sujeitos para que a história se constituísse.

No último painel, uma única palavra servia de mote para a sua construção "implicação". O grupo definiu quatro espaços no papel e, em cada um, desenhou uma tela de computador representando determinados procedimentos utilizados frequentemente em informática. Na primeira tela estava ressaltado o comando "Shift+Del", um pequeno quadrado com o desenho da letra H e a palavra "Histórico" escrita abaixo, com o cursor apontado para essa inscrição. No quadrante da 
direita, outra tela trazia a seguinte pergunta - Tem certeza de que deseja excluir permanentemente o "Histórico" antes de pesquisar? O cursor desta tela estava sobre a palavra SIM. Na terceira tela havia outra frase - Impossível excluir permanentemente o "Histórico" antes de pesquisar. Abaixo, uma caixa escrita OK com o cursor sobre ela. A quarta tela trazia a inscrição GOOGLE e, abaixo, três caixinhas com as seguintes mensagens: "Constituição do sujeito"; "Pesquisar"; "Estou com sorte". Na exposição deste painel, o grupo sinalizou a positividade da implicação quando demonstrou que seria impossível não considerar a história na constituição dos sujeitos, além de associar a pesquisa a este processo.

Os painéis apresentados sintetizaram os debates em torno do tema proposto de forma intensa. O último painel foi considerado importante pela possibilidade de, através de uma linguagem com a qual todos guardam grande intimidade, tratar do tema da implicação, resgatando conteúdos dos demais painéis. A força das imagens se revelou importante na consolidação do aprendizado dos elementos teóricos que foram apresentados no início da unidade do curso. A perspectiva da implicação, tema central desta etapa da disciplina, foi proposta como experiência aos alunos, assim como a compreensão da potência comunicativa da imagem e dos signos. Do mesmo modo, se apresentou como tema aos responsáveis pela condução da disciplina, posto a recorrente discussão das afecções em jogo no processo educativo. A análise da implicação foi uma constante em todo o processo, ora agenciada em encontros semanais para avaliação do trabalho desenvolvido e preparação da aula seguinte, ora nas conversas informais que aconteciam durante as aulas, nos intervalos, via e-mails.

A discussão sobre o conceito de implicação, relacionada à produção de imagens pelos diferentes grupos, possibilitou conectar o conteúdo desta aula com outros anteriormente trabalhados, em especial a unidade que tinha como foco a temática constituição do sujeito. As relações estabelecidas partiram da compreensão de que vivemos em um contexto de grande profusão imagética, acelerada com o desenvolvimento das tecnologias da informação e da comunicação. Mas essas imagens não comunicam por si só, demandam esforços para serem compreendidas em sua interconexão e destas com as condições social, histórica, econômica e política que as engendram. Ademais, sendo as imagens signos polissêmicos e polifônicos, uma vez apropriadas em sua significação constituem o psiquismo humano e conotam sua condição semioticamente mediada.

\section{Terceira estratégia: os vídeos}

A última estratégia educativa a ser analisada estava voltada para a perspectiva de intervenção em psicologia social e envolveu os alunos na produção do próprio dispositivo disparador dos debates. Foram constituídos seis grupos e cada um produziu um audiovisual de cinco minutos problematizando temas relacionados às práticas em psicologia social na interface com outros campos: psicologia política; psicologia social-comunitária e saúde; psicologia social e arte; psicologia social e trabalho; psicologia social e práticas educativas; diversidade e violência. 
Foram destinadas quatro aulas para esta unidade. Os vídeos apresentados traziam uma questão disparadora que norteava os debates, coordenados pelos professores. Novamente o tema da implicação se anunciou como importante dado que o material era preparado pelos alunos a partir de sua investigação sobre a questão em foco, deixando, ainda, transparecer o movimento grupal na elaboração, nas escolhas de imagens, de conteúdo e roteiro.

Cada vídeo teve uma característica própria, porém predominaram produções em que uma sucessão de imagens, balizadas pelo ritmo de uma música específica, conduzia o expectador a aproximar-se da temática abordada a partir de uma perspectiva crítica. Em alguns vídeos, as imagens e sons eram intercalados com falas de pessoas entrevistadas pelo próprio grupo (predominantemente psicólogos) ou de programas de reportagem, escolhidos em virtude do estranhamento que poderiam provocar. Questões contemporâneas estiveram presentes na maioria dos vídeos, sendo apresentadas a partir de uma perspectiva de provocar inquietações ao invés de afirmar certezas. Com essas características, os vídeos foram importantes dispositivos para fazer ver e falar - no caso, para provocar o debate e envolver os colegas na discussão sobre as temáticas em foco. Os textos indicados como referência de estudos foram complementados pelos alunos no sentido de garantir o aporte teórico necessário a compreensão da temática.

No vídeo sobre o tema psicologia política os alunos apresentaram um trabalho resultado de entrevistas que realizaram no campus da universidade. Ao caminharem pelos prédios, construções e jardins, dirigiam a estudantes, transeuntes e trabalhadores da construção civil as seguintes indagações: O que é liberdade? O que é democracia? Como respostas traziam definições, ora complexas ora bastante simples e objetivas. O que chamou atenção foi a imprecisão dos conceitos que compreendemos como tão significativos para a cidadania. Na sequência da aula foi debatida a forma como os conceitos de liberdade e democracia são representados pela população e foi introduzido o aporte teórico passível de promover nos alunos a compreensão do exercício da cidadania e sua importância para a ação da psicologia, principalmente quando se trata de intervenções no campo das políticas públicas.

Para representar o tema psicologia social comunitária, os alunos optaram por dirigir-se a uma comunidade tradicional da cidade, uma histórica colônia de açorianos, e entrevistaram moradores e a profissional de psicologia que atua no posto de saúde local. Foi trazido como material para o debate a forma como o atendimento em saúde mental é representado pelos moradores, focalizando uma ação individual. No entanto, no depoimento da psicóloga entrevistada foram apontadas como mais importantes as ações coletivas e em grupo que eram promovidas e o trabalho voltado a promoção da saúde. Assim como em todas as aulas desta unidade, o aporte teórico foi trazido pelos alunos e o debate, conduzido pela professora. Foi identificada uma distância entre a proposta de trabalho da profissional e a percepção do cuidado a saúde mental como uma estratégia que não se localiza somente no tratamento psicoterápico com enquadre individual. 
Para abordar a temática Psicologia social e arte, o grupo de alunos responsável pela produção do vídeo entrevistou artistas urbanos que produzem grafites pelas vias da cidade. A arte em foco nessa produção imagética foi considerada em sua relação com a política, sendo abordadas questões relacionadas à valorização social de alguns tipos de arte e a desqualificação de outras. A relação entre o tema e a psicologia social foi realizada através da exposição de conceitos como estética e relações estéticas, apresentadas pela professora em virtude de dúvidas apresentadas pelos alunos. Embora o vídeo tenha sido importante ferramenta para fomentar o debate, necessário se fez explicitar conceitos e dirimir as dúvidas relacionadas às possibilidades do trabalho em psicologia com a mediação de linguagens artísticas ou via diálogo com questões afins a esse campo.

A relação entre psicologia social e trabalho foi tratada ressaltando suas características na sociedade capitalista. Foram retratadas atividades laborais e entrevistados trabalhadores no campus da universidade, questionando-se as relações coletivas entre empregados de um mesmo espaço, a jornada e condições de trabalho e possíveis afecções que pudessem ser associadas à forma como o trabalho é exercido. Foi identificada uma relação clara com os argumentos do texto base, indicado no plano de curso da disciplina, que aponta os efeitos da parcialização ou fragmentação do trabalho na saúde mental dos trabalhadores.

No que diz respeito às práticas educativas, o grupo de alunos retratou as diferenças na vivência de alunos apontando alguns fatores que atravessam a experiência educacional como a pobreza e a violência. Foram trazidos dados sobre escolarização e trechos de filmes e documentários que apresentavam críticas à situação da educação brasileira. Foram marcadas as diferenças sociais e como exemplo foi trazido o depoimento de um estudante que, interessado em letras de música de hip-hop, se envolveu no processo de aprendizado da leitura e escrita, dando assim, significado para a vivência escolar. No debate promovido foi trazida como tema a distância entre a escola e as necessidades de mudanças requisitadas pela sociedade.

Para tratar da temática diversidade, o grupo responsável elaborou um vídeo a partir de trechos de filmes e reportagens sobre homofobia. Alguns filmes selecionados eram já conhecidos de grande parte dos alunos, porém a montagem elaborada pelo grupo conferiu ao material uma característica de novidade que despertou interesse e suscitou o debate crítico sobre o tema. Causou maior impacto a apresentação de uma suposta enquete, realizada com moradores do Rio de Janeiro, sobre a reivindicação de que nordestinos fossem enviados de volta ao seu estado natal. Embora se tratasse de reportagem sobre causa fictícia, produzida para verificar a reação dos entrevistados, causou surpresa o número de pessoas dispostas a assinar o suposto abaixo-assinado com a absurda reivindicação. A discussão desse trecho do vídeo permitiu relacionar com os textos indicados para leitura em que pesquisadores analisam a intolerância étnica e a questão dos preconceitos, temas caros à psicologia social.

A discussão desse vídeo, de certo modo, aqueceu o grupo para a leitura/escuta do vídeo seguinte, que tinha como tema a violência. Também fazendo uso do recurso de recortes de reportagens e sua organização em uma sequência narrativa, as 
imagens apresentadas tiveram como foco vários tipos de violência: de gênero, étnica, em contextos de trabalho, urbana. A violência foi trabalhada como um elemento da vivência contemporânea sendo marcante o questionamento de sua naturalização.

\section{Avaliação Como modo de Produção de aberturas e ReFlexões}

Ao final da disciplina foi promovido um processo de avaliação do aprendizado de conceitos e do aporte teórico utilizado. Foram apresentados aos alunos cinco dispositivos que traziam uma pergunta relacionada a uma imagem ou charge. Aos alunos foi solicitado escolher dois dispositivos e elaborar uma reflexão com base na referência bibliográfica utilizada na disciplina, aprofundando o conteúdo sugerido na indagação contida no dispositivo. Importante sinalizar que essa avaliação foi realizada durante o período de uma aula, podendo o aluno apoiar-se no material bibliográfico, produzindo, a partir do dispositivo apresentado, novas conexões conceituais e teóricas, exercitando a formulação de indagações próprias.

Em seguida, foi solicitada aos alunos uma avaliação escrita dirigida à identificação de um possível movimento/deslocamento engendrado no contato com a disciplina de Psicologia Social II. Para tanto, foi sugerida a seguinte reflexão: Faça uma autoavaliação de seu movimento neste semestre. Você percebe algum deslocamento, alguma mudança em suas concepções? Em que sentido, em que direção? A disciplina de Psicologia Social II contribuiu para esse movimento? Como?

O foco, neste momento da análise dos efeitos das estratégias educativas neste grupo de alunos, foi dirigido aos textos escritos como resposta às indagações apresentadas, buscando identificar, nos discursos dos alunos, os caminhos percorridos por cada um.

Foram encontrados posicionamentos que focalizavam a posição do aluno diante do estudo da psicologia social com enfoque crítico; a articulação entre o conteúdo da disciplina e uma mudança subjetiva; uma modificação na concepção de psicologia e, ainda, observações sobre as estratégias utilizadas no processo educativo.

Entre os 38 alunos que participaram dessa atividade, identificamos três que não se mobilizaram com a perspectiva da disciplina afirmando falta de identificação com os conteúdos veiculados, o que promoveu pouco investimento acadêmico. A argumentação apontava como causa deste sentimento o caráter político das discussões. Um deles traduziu este sentimento com a seguinte afirmativa: "muitas das minhas posições se radicalizaram, pois, na minha interpretação, meus entendimentos divergem da grande parte da turma e da professora" (A24). Outro depoimento apontou para a falta de neutralidade nos debates, assim expresso: "pensei que fossemos discutir a formação de movimentos e entendê-los com imparcialidade" (A19). Nessa mesma linha pode ser trazido outro depoimento de uma aluna (A38) que ressaltou a dificuldade de estar "aberta", posto que os textos não lhe atraíam. Fez uma indicação importante para a construção da dinâmica educativa ao apontar que faltava uma mediação que pudesse facilitar o contato com uma nova base epistemológica. 
Um quarto aluno (A20) afirmou contrariedade no início do semestre com relação aos conteúdos, qualificada por este como preconceito, mas indicou uma mudança nessa forma de olhar afirmando que a disciplina auxiliou na ampliação de seus horizontes. Uma perspectiva semelhante de mudança a partir da experiência pode ser encontrada no depoimento de outro aluno que aponta: "esta disciplina, no início, surgiu-me como contrária ao que estudo" (A1). No entanto, se surpreendeu pela identificação promovida com os debates e com as leituras.

A percepção de uma prática inviável ou irrealizável foi encontrada em outro depoimento, quando a aluna revelou que "ficava com a impressão de que havia muitas críticas e poucas soluções" (A3). Na sequência de seu texto, no entanto, revelou que ao imaginar os questionamentos em sua prática profissional começou a ver novas possibilidades de atuação, concluindo com a afirmação de que sua prática pode ser transformadora.

Nos demais 32 textos de avaliação elaborados pelos alunos, a tônica foi a identificação de mudanças ocorridas a partir da disciplina. Um dos discursos focou uma mudança subjetiva, promovida pelo contato com explicações para os eventos sociais com base na valorização da historicidade e no questionamento da naturalização de práticas sociais: "olhar mais amplo/aberto/abrangente para certos temas, ou melhor, obter uma forma mais integrada para analisar situações diversas" (A37).

Outros textos exemplificam, ainda melhor, essa percepção de mudança subjetiva e foram aqui agrupados em função das semelhanças apresentadas na perspectiva de análise: "Meu movimento foi no sentido de uma curiosidade cada vez mais crescente em busca de novas perspectivas e na maior percepção de minha relação com o mundo" (A6). "Saio da disciplina como uma pessoa mais crítica e disposta a questionar e problematizar aquilo que está presente no mundo" (A22). "Tive oportunidade de questionar verdades absolutas que eu trazia comigo. Pude questionar muitas coisas e abrir coisas que eu nem sabia existir. Foram oportunidades ricas de questionamentos e de construções" (A15). Um último depoimento nesta linha de pensamento associa essa mudança à construção de um caminho profissional, quando o aluno afirma que: "acredito que a disciplina tenha contribuído bastante com minha vida no sentido de me esclarecer, principalmente, sobre a prática da psicologia e sua complexidade e responsabilidade. Me fez refletir sobre o meu papel nisso tudo" (A34).

Uma intervenção na constituição de concepções fundamentais para a psicologia social pode ser exemplificada no depoimento de outro aluno:

as discussões possibilitadas contribuíram de maneira fundamental para solidificar minha compreensão do homem/ do humano e de que maneira a Psicologia pode e deve se posicionar frente as angústias e sofrimentos que permeiam todos nós. Compreender melhor como o homem se constrói, se subjetiva em meio a objetivação de sua existência e suas ações, só me foi possível por meio do contato com você (A21). 
Uma variação desse discurso, característica da maior parte dos textos, aparece quando os alunos apontam para os efeitos diretos dessa experimentação na constituição de uma prática profissional problematizadora. $\mathrm{O}$ destaque para alguns textos possibilita uma maior compreensão do processo: "Percebo que a disciplina contribuiu para o exercício de uma visão crítica. Acho que o ponto mais importante é a desconstrução" (A2). "A disciplina me apresentou a psicologia sob uma ótica mais política. Permitiu-me avaliar o papel de psicólogo enquanto sujeito político, comprometido com a realidade social vigente" (A35). "Percebo uma enorme diferença no sentido de olhar os sujeitos e o modo como são construídos. Passei a não me encantar tanto com as coisas, mas me colocar em uma posição crítica, sempre reflexiva" (A33). "Perceber que nem sempre temos as respostas para as perguntas que fizemos. Aprendi a nunca deixar de me questionar, de refletir sobre novas possibilidades de existência a partir de nossa prática profissional" (A4). "A disciplina me tornou esperançosa. Minha prática pode ser transformadora" (A3).

Por último, pode ser ressaltada a importância dos debates em sala e das dinâmicas sinalizada pelos alunos, a exemplo do depoimento que afirma que "as discussões foram profundas e atingiram pontos básicos, porém cruciais que pautam quaisquer reflexões. Aquilo que muitas vezes fica encoberto, na disciplina foi apontado e debatido até o limite possível" (A23). A possibilidade de articulação entre conceitos pode ser identificada na afirmação de que "foi interessante ler textos e ideias que antes estavam desconectados e que juntos faziam uma imagem muito mais sólida e bonita" (A28). Essa ideia pode ser complementada pela afirmação de que "[...] consegui entender, além de uma visão da formação do indivíduo, possibilidades de atuação e questionamento do psicólogo, por meio dos debates e do vídeo, pois eu fui bem próximo da realidade (psi comunitária)" (A29).

Esta última atividade foi idealizada buscando-se um mecanismo que pudesse promover, como efeito, uma síntese do processo educativo, importante para a reflexão de educandos e educadores sobre sua experiência. Aqui é considerada, como elemento dessa síntese, a análise do lugar social, da potência da fala e das ações no coletivo por parte de cada agente social. Para Costa e Coimbra (2008, p. 127):

[...] colocar em análise algumas das linhas duras - da instituição formação - em especial da psicologia e da educação, é promover desvios de um ofício, de um saber, que nos constitui em sujeitos dos "especialismos". Portanto, nessa perspectiva, está em análise, certamente, o lugar e o fazer da psicologia e da educação, no sentido de as duas poderem se submeter aos "especialismos" ou ir além de traduzi-los na sua dimensão teórico-prática.

As discussões pautaram-se pela tensão entre potência e impotência, entre os limites de se querer fazer algo diferente e as condições dessas práticas outras virem a ser engendradas. Fazer emergir as angústias, as frustrações, bem como as utopias, visando problematiza-las, tenciona-las, se apresentou como condição da análise da implicação de todos no processo educativo e ao mesmo tempo no projeto de vir a ser que ali se encontrava em foco. Os resultados das estratégias 
educativas aqui analisadas, por sua vez, não evidenciaram respostas a essas angústias, mas sua própria problematização, o que consideramos positivo na medida em que engendra movimentos.

\section{CONSIDERAÇões FINAIS}

Os discursos dos alunos e suas produções imagéticas evidenciaram deslocamentos no sentido de sua concepção de psicologia social, evidenciando o movimento de produção conjunta e apropriação de uma concepção de psicologia social como campo historicamente constituído e o reconhecimento de sua potência de intervenção. As estratégias de ensino, ao contemplarem aulas expositivas, atividades estéticas de criação de imagens gráficas e produção de vídeos, possibilitaram tanto a compreensão do referencial teórico trabalhado como a vivência de situações em que a perspectiva de psicologia social como intervenção em sua dimensão inventiva eram evidentes. Foram estratégias eleitas em virtude da compreensão de sua potência como dispositivos para a formação ética e estética em psicologia, e os discursos dos alunos objetivados nas autoavaliações, ainda que com algumas discordâncias, possibilitaram evidenciar o acerto das escolhas. Podem vir a produzir os mesmos efeitos com outros alunos, em outros contextos, mas não há como assegurar isso: no campo do vivido, a potência dos dispositivos e o que agenciam é da ordem dos possíveis, sendo necessária a sua reinvenção constante bem como o investimento na concretização de bons e profícuos encontros.

\section{Nota}

${ }^{1}$ A dialogia consiste no "espaço de luta entre vozes sociais (uma espécie de guerra dos discursos), no qual atuam forças centrípetas (aquelas que buscam impor certa centralização verboaxiológica por sobre o plurilinguismo real) e forças centrífugas (aquelas que corroem continuamente as tendências centralizadoras, por meio de vários processos dialógicos tais como a paródia e o riso de qualquer natureza, a polêmica explícita ou velada, a hibridização ou a reavaliação, a sobreposição de vozes etc)" (FARACO, 2003, p.67).

\section{REFERÊNCIAS}

BARROS, R. D. B. Dispositivos em ação: grupos. In: LANCETTI, A. (Org.). SaúdeLoucura: subjetividade. São Paulo: Hucitec, 1997. v. 6, p. 183-191.

BRAIT, B. (Org.). Alguns pilares da arquitetura bakhtiniana. In: . Bakhtin: conceitos chave. São Paulo: Contexto, 2005. p. 07-10.

COSTA, E. A. P.; COIMBRA, C. M. B. Nem criadores, nem criaturas: éramos todos devires na produção de diferentes saberes. Psicol. Soc., Porto Alegre, v. 20, n. 1, p. 125-133, abr. 2008.

DELEUZE, G. ¿Que és un dispositivo? Tradução de Wanderson Flor do Nascimento. In: Michel Foucault, filósofo. Barcelona: Gedisa, 1990. p. 155-161. Disponível em: <http://escolanomade.org/pensadores-textos-e-videos/deleuzegilles/o-que-e-um-dispositivo>. Acesso em: 21 jun. 2012. 
FARACO, C. A. Linguagem \& Diálogo: as ideias linguísticas do Círculo de Bakhtin. Curitiba: Criar, 2003.

FREIRE, P. Pedagogia do oprimido. Rio de Janeiro: Paz e Terra, 1970.

FREIRE, P. Pedagogia da autonomia: saberes necessários à prática educativa. Rio de Janeiro: Paz e Terra, 2009.

GROFF, A. R.; MAHEIRIE, K.; ZANELLA, A. V. A constituição do(a) pesquisador(a) em ciências humanas. Arquivos Brasileiros de Psicologia, Rio de Janeiro, v. 62, n. 1, p. 97-103, 2010.

MAIRESSE, D.; FONSECA, T. M. G. Dizer, escutar, escrever: redes de tradução impressas na arte de cartografar. Psicol. estud., Maringá, v. 7, n. 2, p. 111-116, dez. 2002.

NASCIMENTO, M. L.; COIMBRA, C. M. B. Análise de implicações: desafiando nossas práticas de saber/poder. In: GEISLER, A. R.; ABRAHÃO, A. L.; COIMBRA, C. M. B. (Org.). Subjetividade, violência e direitos humanos: produzindo novos dispositivos na formação em saúde. Niterói, RJ: EDUFF, 2008. p. 143-153.

PAULON, S. M. A análise de implicação como ferramenta na pesquisaintervenção. Psicol. Soc., Porto Alegre, v. 17, n. 3, p. 18-25, 2005.

ROCHA, M. L. da. Inclusão ou exclusão? Produção de subjetividade nas práticas de formação. Psicol. estud., v. 13, n. 3, p. 477-484, set. 2008.

ROCHA, M. L. da; AGUIAR, K. F. de. Pesquisa-intervenção e a produção de novas análises. Psicol. cienc. prof., [S.1.], v. 23, n. 4, p. 64-73, dez. 2003.

RODRIGUES, H. B. C. Sobre as histórias das práticas grupais: explorações quanto a um intrincado problema. In: JACÓ-VILLELA, A. M.; MANCEBO, D. (Org.). Psicologia Social: abordagens sócio-históricas e desafios contemporâneos. Rio de Janeiro: EdUERJ, 1999. p. 111-165.

SCHLINDWEIN, L. M.; SIRGADO, A. P. (Org.). Estética e pesquisa na formação de professores. Itajaí, SC: UNIVALI; Maria do Cais, 2006.

SOARES, F. M. Uma experiência de intervenção em um projeto cultural: o psicólogo e a defesa dos direitos humanos nas instituições socioeducativas. Fractal, Rev. Psicol., Niterói, v. 23, n. 1, p. 171-190, 2011.

ZANELLA, A. V.; SAIS, A. P. Reflexões sobre o pesquisar em psicologia como processo de criação ético, estético e político. Análise Psicológica, Lisboa, v. 26, n. 4, p. 679-687, out. 2008. 
